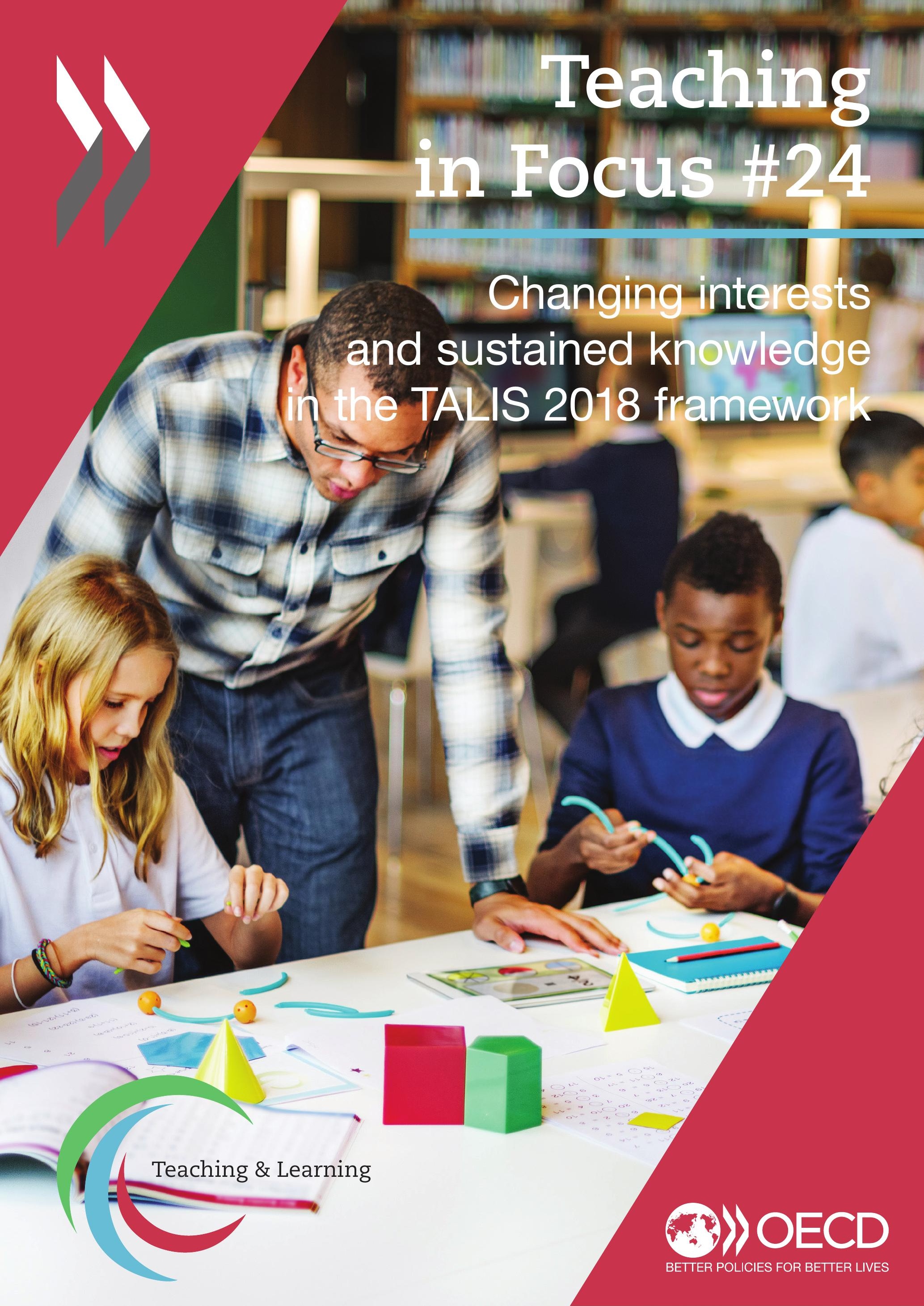




\section{Changing interests and sustained knowledge in the TALIS 2018 framework}

- TALIS 2018 is the third cycle of this international survey of teachers and school leaders.

- The main data were collected in late 2017/early 2018, and initial results and data are expected to be published in June 2019.

The survey's conceptual framework reflects major concepts from research literature, as well as policy interests, and was developed by researchers in consultation with international stakeholders and participating countries/economies.

- The 2018 framework is organised under 11 themes that address both emerging issues in teaching and learning including new themes of equity and diversity and innovation - and enduring issues from the two previous cycles in 2008 and 2013.

- TALIS 2018 focuses on lower secondary education, but also provides information about primary and upper secondary education for those countries that choose either of the options that address these levels.

This Teaching in Focus brief introduces the framework for the 2018 OECD Teaching and Learning International Survey (TALIS). TALIS was initiated in 2008 as an international, large-scale survey of school teaching workforces, teaching conditions, and learning environments, principally based on original work by the OECD. Informed by multiple site visits, interviews and observations, the publication Teachers Matter: Attracting, Developing and Retaining Effective Teachers (OECD, 2005) is the driving policy perspective on TALIS to date. The "Teaching and Learning International Survey (TALIS) 2018 Conceptual Framework" (OECD, 2018a) was jointly authored by the international research consortium and members of the questionnaire expert group. Its main areas and themes are represented in Figure 1.

Figure 1. Conceptual mapping of themes in TALIS 2018

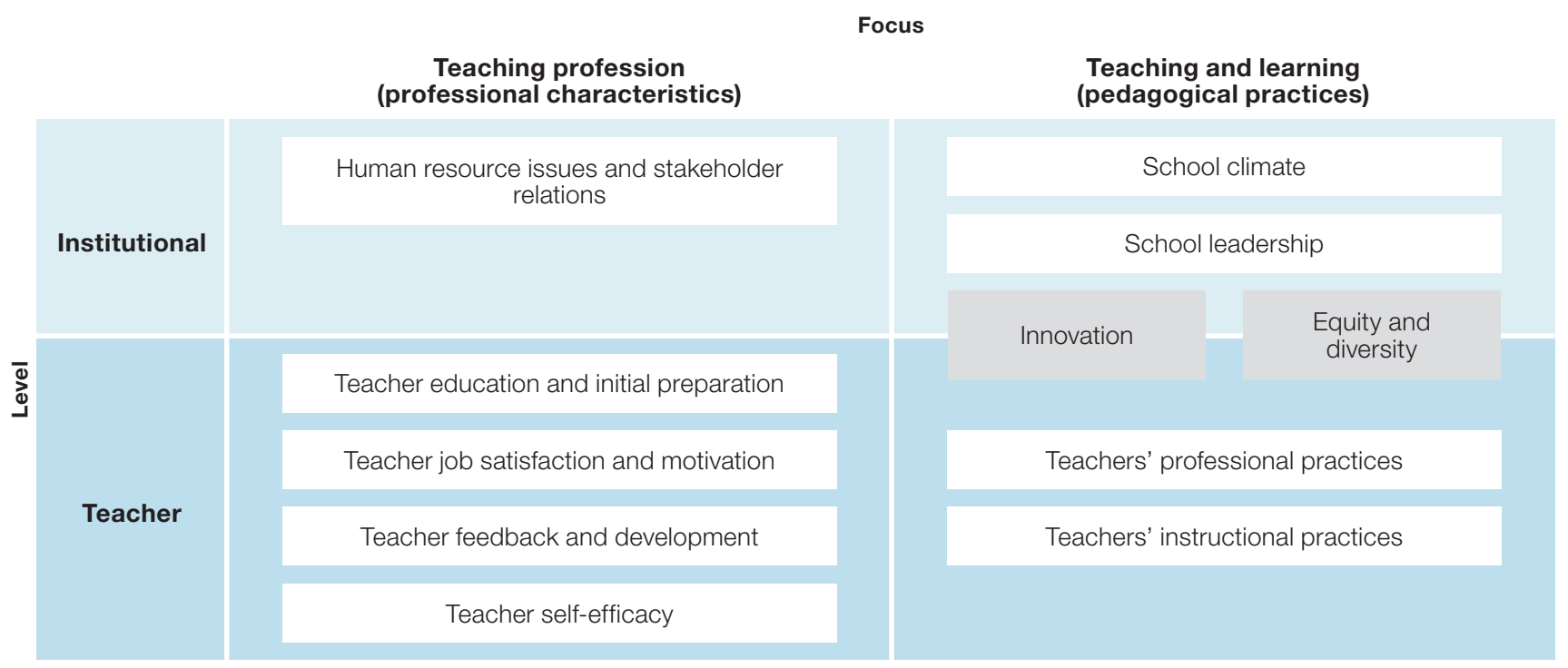

\section{Conceptual framework: The science behind TALIS}

The TALIS 2018 conceptual framework addresses themes and priorities related to professional characteristics and pedagogical practices at the institutional and individual level. At the teacher level, these themes are instructional practices and professional practices that directly impact how students experience education. These practices are influenced by teacher education background and initial preparation, teacher feedback and development, self-efficacy, and job satisfaction and motivation. At the institutional level, the themes are human resource issues and stakeholder relations, school leadership, and school climate. The framework also incorporates emerging policy and research interests related to innovation and equity and diversity. A major difference between TALIS and other analyses based on general occupational labour data and statistics is that TALIS enables analyses on how implemented policies intersect with the professional attitudes and behaviours of teachers and principals at the individual, school, and system level. 
Figure 1 shows the allocation of themes to one of four clusters based on whether they relate to the institutional (including system) level (top) or the teacher level (and their work in classrooms, bottom), as well as whether they relate to the more professional and workforce related aspects on the left or the pedagogical aspects on the right. Each theme could also be related to other dimensions but, in order to describe the basic structure of the conceptual framework, the most important links and associations are shown.

TALIS is especially useful for capturing how individual teachers and principals implement and react to institutional-level educational policies and standards. For example, it is through self-reports such as TALIS that we can see how teachers may find that formal training did not prepare them enough for their classroom teaching, despite system-level policies mandating professional education to certify teachers. Consequently, teachers may report a desire for additional professional development (OECD, 2013). These varied experiences with system policies by individual teachers has led researchers like Price and Weatherby (2018) to explain why teachers may feel undervalued as professionals and eventually leave teaching. They investigated the status of the teaching profession in terms of four domains of knowledge-worker (professional benchmarks, professional discretion, room for promotion, and workplace conditions) to show that these vary within and between countries.

TALIS focuses on factors that are amenable and malleable to change at the system, school, and/or teacher level. For example, asking teachers about how their principals allow them to be part of school decisions, and how such involvement relates to teachers' self-esteem and commitment, connects to effective teaching, which could be improved with directed action. Linking back to TALIS' roots (OECD, 2005), the four quadrants in Figure 2 relate to five policy areas:

- Teachers' instructional practices and teacher professional practices correspond with the policy area "effective teaching".

- Teacher education and initial preparation, teacher feedback and development, teacher self-efficacy, and teacher job satisfaction and motivation are linked to "developing teachers".

- School leadership and climate are linked to "school effectiveness".

- Finally, human resource issues and stakeholder relations are linked to "attracting teachers" and "retaining teachers".

Figure 2. Correspondence between the conceptual map and policy areas

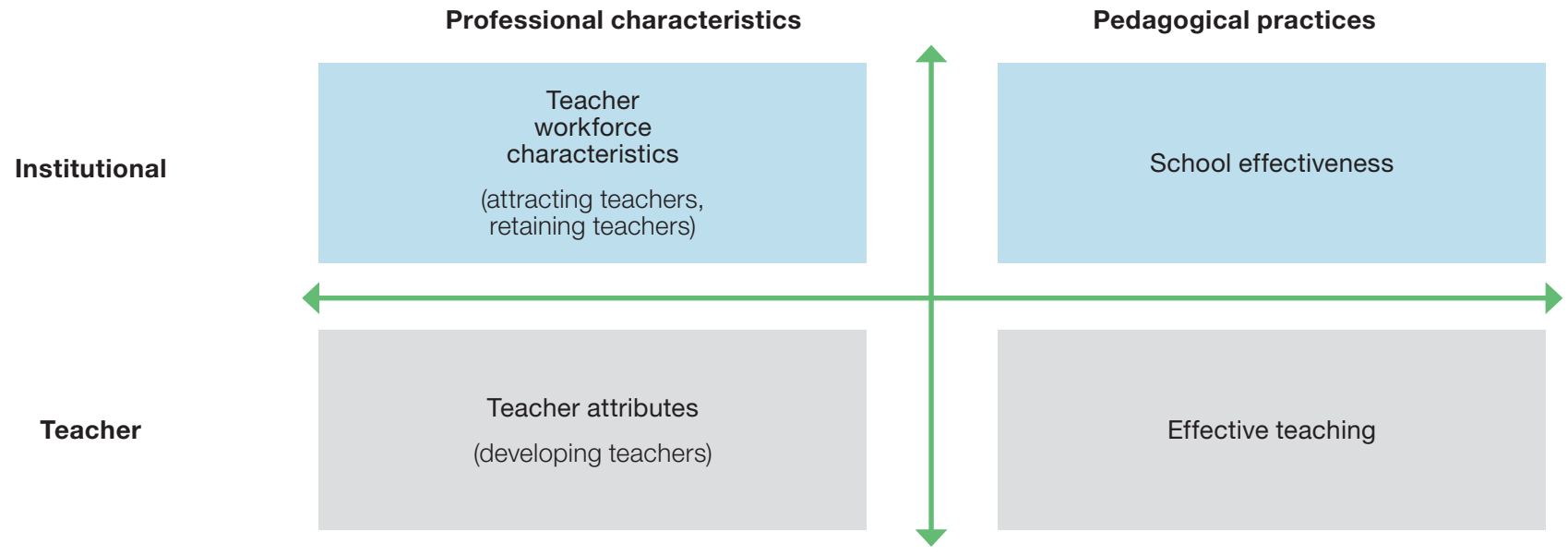

More detailed illustrations, priority areas and the mapping between these and the initial policy aspects driving TALIS to date are included in the full conceptual framework, along with an exploration of the limitations involved in such work. TALIS has the advantage of providing insights based on large volumes of respondents: more than 240000 teachers and 13000 principals in the 2018 cycle across ISCED levels 1, 2 and 3. However, as analyses are generated from self-reports, it is advisable to also compare and contrast results with those from other sources, such as the TALIS Video Study in nine countries (OECD, 2018b), small-scale observational studies and other methods.

\section{Sustained knowledge: Including repeated measures}

The TALIS 2018 conceptual framework builds on the previous two cycles and underpins the survey's focus on instructional and institutional conditions that enhance student learning, while describing how these vary both within and across countries/ economies and over time. Retaining important issues over time is central to this unique survey, which has often been described as the "voice of teachers" as it allows countries to measure and monitor information, perceptions and attitudes in a "nomological" network, i.e. it shows how concepts (constructs) of interest in a study become visible or evident, and how they are connected to one another.

The 2013 survey repeated the 2008 survey and used many of the same questions to facilitate comparisons. Although the themes, topics and headings of TALIS 2018 are like those addressed by TALIS in the past (OECD, 2013) there are substantial differences regarding the depth and scope of the questions and indicators (e.g. with respect to the existence of particular structure, how it works and what perceived impact it had on teachers). 
In TALIS 2013, options were introduced for countries to survey teachers at the primary and upper secondary levels and teachers in schools that had taken part in the Programme for International Student Assessment (PISA). In the development of the primary (ISCED 1) and upper secondary (ISCED 3) optional surveys, questions were kept the same as the lower secondary (ISCED 2) questionnaires to enable comparisons, despite the different contexts.

\section{Changing interests: Keeping TALIS relevant for policy}

TALIS 2018, like TALIS 2013, developed and included new material to remain relevant to emerging policy interests and to cover information gaps based on, but not limited to, insights that continue to arise from prior TALIS findings, emerging global politics, and the impact of newly implemented policies. This can take the form of new themes or new aspects of enduring themes, for example, themes related to the increasing issue in many countries about severe shortages of teachers and candidates for initial teacher education, teachers prematurely leaving the career, or other aspects related to the attractiveness of the profession.

Two themes are new to TALIS in 2018: innovation and equity and diversity (both highlighted in grey in Figure 1). As cross-cutting issues related to, for instance, teachers' instructional practices or school climate, ongoing dialogue with the TALIS Governing Board (TGB) showed that more effort should be put into covering these topics given their relevance for and contribution to policy. Indicators related to teachers' openness to adopting innovative practices, perceptions regarding the barriers and incentives for the adoption of innovation, and various perceptions and provisions at the school and classroom level regarding the diversity of students (related to gender, culture or socio-economic dimensions) were developed.

These two areas are likely to be those most obviously linked to contemporary discussions about the shifting landscape of education from traditional subject matter towards the development of socio-emotional and life skills. TALIS can contribute to evaluating the extent to which the United Nations Sustainable Development Goals are met, especially Target 4.c, which addresses the role of teachers in ensuring quality education.

TALIS 2018 also includes changes within themes, such as in school leadership, which has been informed by concepts concerned with distributed leadership and teacher feedback and development, and which then introduced ideas that had emerged since the planning for TALIS 2013. Other changes in TALIS 2018 reflected perspectives that came from analyses of data from earlier cycles.

TALIS aims to address methodological issues common to large-scale surveys in general, such as the comparability of estimates across countries and groups within countries, or alternative types of questions better suited to capturing actual teaching practices, given the anxiety that teachers' reports may not always coincide with what teachers actually do in their classrooms (see also OECD [2015] for a discussion of this issue).

\section{Collaboration: Developing the conceptual framework}

As with any quality survey, the conceptual framework had to guide the development of the survey instruments and operations. Its primary purpose was to provide the integrated theoretical and policy underpinning and articulate the research focus and links to existing knowledge and evidence. TALIS 2018 will, therefore, gather information about teacher characteristics, conditions, practices, and learning environments that research evidence and practitioner experience suggest contribute to positive student learning. However, the framework also recognises that positive student learning is also influenced by factors that surveys such as TALIS cannot examine through teacher self-reports.

The framework's first section covers the general purpose and policy relevance of TALIS, which is to describe teaching and learning conditions, to identify the relationships among components of those conditions, and to identify and describe how teaching and learning conditions and relationships vary within and across TALIS participants and over time. This section now also includes aspects of TALIS' development and major insights since the first survey in 2008.

The second section collates the knowledge relevant to themes and the main indicators. The breadth of academic and policy research in education related to TALIS, or that TALIS has made possible, is extensive. This is, hence, the most valuable section to the instrument development process and subsequent piloting and testing. This section has also influenced, or was influenced, by TALIS-related projects, such as the TALIS Video Study, the TALIS Starting Strong Survey (focusing on staff and centre leadership aspects in ISCED 0.2 and for under 3-year-olds), the OECD's work on initial teacher education and related effectiveness, and a new focus on aspects of teacher well-being. Finally, synergies between TALIS and PISA were considered, although both programmes have somewhat separate goals and approaches (see also OECD, 2015).

The final section provides a very condensed look at the design of TALIS 2018, the overarching definitions, sample and operational approaches, the field trial and main survey designs, and - in the interests of establishing valid, reliable, and comparable cross-sectional and over-time indicators - the relevance and quality of the measures used in TALIS. Box 1 includes some broad parameters of the study. 


\section{Box 1. What is TALIS?}

The Teaching and Learning International Survey (TALIS), established in 2008, is the first major international survey of teachers and school leaders on their working conditions and the learning environments at their schools. It is designed to help countries face diverse challenges, learn from each other and advance policy.

TALIS 2018, for which the first results will be released in mid-2019, has continued to focus on lower secondary education with the added options of primary and upper secondary levels. It now covers close to 50 countries around the world.

Key parameters in brief:

- International target population: lower secondary education (ISCED level 2) teachers and the principals of their schools. A teacher is defined as a person whose professional activity involves the transmission of knowledge, attitudes and skills to students enrolled in an education programme.

- International options: primary (ISCED level 1) and/or upper secondary (ISCED level 3) education; school-level link to PISA 2018 aimed at teachers teaching 15-year-olds in schools taking part in PISA 2018.

- Sample size: minimum 200 schools per country, 20 teachers in each school.

- Sampling: probability samples of schools and of teachers within schools.

- Target response rates: $75 \%$ of the sampled schools, aiming for a $75 \%$ response from all sampled teachers in the country.

- Questionnaires: separate, adaptable questionnaires for teachers and principals, each requiring around 45-60 minutes to complete.

- Modes of data collection: self-administered on line or using paper and pencil.

- Phases: pilot study (focus group pre-testing), field trial (with experiments), and main data collection.

More information is available at: www.oecd.org/education/talis

Determining what knowledge to keep in the survey between years, and which questions to cycle out of the survey to make way for new and changing interests, is part of an extensive dialogue between policy makers, researchers, and institutional representatives. As part of the process, the framework developers consulted extensively with a core group of scholars and additional researchers familiar with regional contexts, specific sectors of formal education (e.g. vocational education and training) and with the span of education from primary to upper secondary levels. The drafts of the framework were discussed with the TGB and national project managers for local applicability and the completeness of the underpinnings and perspectives, both for the framework and questionnaire contents. The dialogue then turned into compromise, i.e. which interests seem the most compatible with the TALIS orientation and which interests may fit better with sibling projects. A series of difficult decisions were necessary, since more issues were initially in scope than could be included in questionnaires of reasonable length.

The framework successfully guided the survey development, the consortium's analysis plan and the OECD's reporting plans, and, hopefully, will also guide the many papers and secondary analyses that will follow publication of the initial results and data in June 2019. Analyses of the 2008 and 2013 databases have yielded many insights, and the development of comprehensive plans for analysis and reporting for TALIS 2018 will help to lay the foundations for thematic reporting and other potential areas of research using the TALIS databases in the years to come.

\section{The bottom line}

The value of TALIS relates to three major aspects, all encapsulated in the conceptual framework:

- The TALIS conceptual development is grounded in real-world policy interests, detailed needs for data that can address complex questions, and the strong willingness of teachers and principals in participating countries and economies to provide this information.

- The TALIS conceptual framework provides a rich scientific basis of existing research, empirical insights and conceptual connections to drive the development of the survey instruments and reports for TALIS 2018 and future cycles.

- The development of TALIS 2018, similar to previous cycles, took place in a fruitful dialogue between governments in close to 50 countries and economies, an international research consortium - led by the International Association for the Evaluation of Educational Achievement (IEA), the Australian Council for Educational Research and Statistics Canada as consortium partners - teachers' unions, the European Commission and the OECD Secretariat. 
Contact points

Ralph Carstens (ralph.carstens@iea-hamburg.de)

John Ainley (john.ainley@acer.org)

Heather Price (hprice@alumni.nd.edu)

\section{To learn more}

OECD (2018a), "Teaching and Learning International Survey (TALIS) 2018 Conceptual Framework”, OECD Education Working Papers, No. 187, OECD Publishing, Paris, https://doi.org/10.1787/799337c2-en.

OECD (2018b), "What does teaching look like?: A new video study", Teaching in Focus, No. 20, OECD Publishing, Paris, https://doi.org/10.1787/948427dc-en.

OECD (2015), "Joint Conceptual Framework for TALIS and PISA Synergies", No. EDU/INES/TALIS(2015)6 (internal document), Directorate for Education and Skills, OECD, Paris.

OECD (2013), Teaching and Learning International Survey, TALIS 2013: Conceptual Framework, OECD, Paris, http://www.oecd.org/education/school/TALIS\%20Conceptual\%20Framework FINAL.pdf.

OECD (2005), Teachers Matter: Attracting, Developing and Retaining Effective Teachers, Education and Training Policy, OECD Publishing, Paris, http://dx.doi.org/10.1787/9789264018044-en.

Price, H. and K. Weatherby (2018), "The global teaching profession: how treating teachers as knowledge workers improves the esteem of the teaching profession", School Effectiveness and School Improvement, Vol. 29/1, pp. 113-149.

This paper is published under the responsibility of the Secretary-General of the OECD. The opinions expressed and the arguments employed herein do not necessarily reflect the official views of OECD member countries.

This document, as well as any data and map included herein, are without prejudice to the status of or sovereignty over any territory, to the delimitation of international frontiers and boundaries and to the name of any territory, city or area.

You can copy, download or print OECD content for your own use, and you can include excerpts from OECD publications, databases and multimedia products in your own documents, presentations, blogs, websites and teaching materials, provided that suitable acknowledgment of OECD as source and copyright owner is given. All requests for commercial use and translation rights should be submitted to rights@oecd.org.

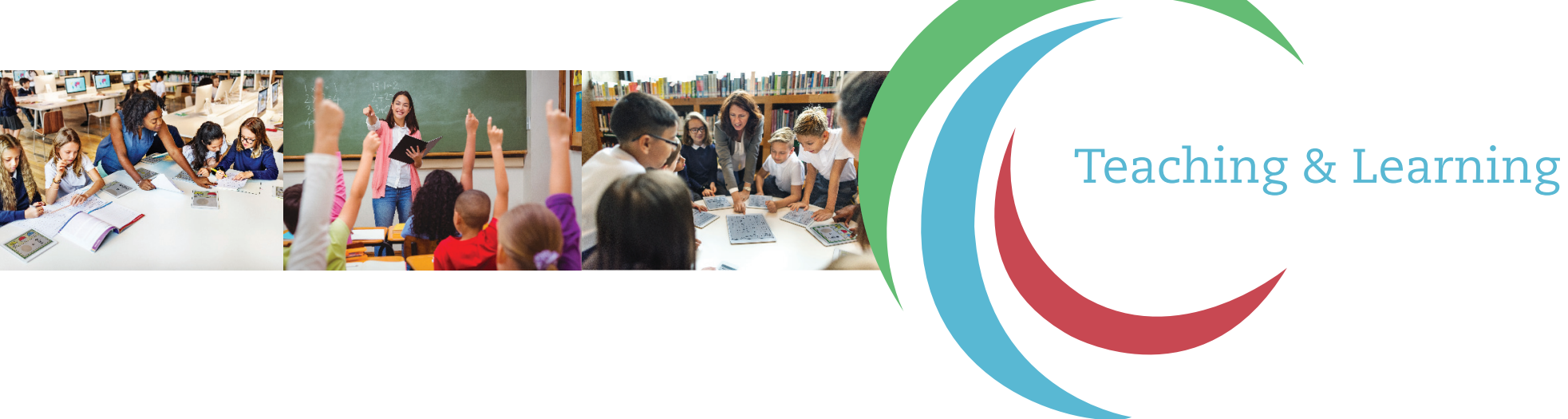

